\title{
The Types of Injury, Regions and Frequency in Athletes Participating Universities Taekwondo Championchip
}

\author{
Ekrem BOYALI ${ }^{1}$, Süleyman PATLAR ${ }^{1}$, Murat ERGİN ${ }^{2}$, Ali Osman KIVRAK¹, \\ Tayyar KARADAĞ ${ }^{1}$, Hasan YILDIZ ${ }^{1}$, Ali Kemal BOZTAŞ' ${ }^{1}$, Süha \\ GÜNDOĞDU1
}

\author{
${ }^{1}$ Selcuk University, High School of Physical Education and Sport, Selçuklu, Konya \\ ${ }^{2}$ Kırıkkale Üniversitesi, Spor Bilimleri Fakültesi, Kırıkkale \\ Corresponding author:Dr.EBOYALI e-mail:eboyali@selcuk.edu.tr
}

\begin{abstract}
This study aims to determine the rates of injuries, the types of injuries and what part of the body is mostly injured in professional taekwondo sportsmen during competitions. This study involves 287 sportsmen participated in the interuniversity Taekwando championship in Ordu. Injuries during a match of the championship was determined by a team. The characteristics and types of injuries, the sportsmen's verbal expressions were registered by a pre-determined team, and it was mentioned about how these injuries occurred, in which part of the body the injuries were seen. Among 287 sportsmen in this study, 178 sportsmen were male, 109 ones were female. 46 universities took part in this championship. The championship lasted three days and total 271 competitions were done. 539 injuries were determined in total. The mostly seen type of injury was hematoma (43\%), the mostly injured part was in lower extremities $416(77 \%)$, most of the injuries were ones seen in defense (36\%). No injuries were not observed in neck, shoulder, spine or trunk and cerebral injuries were not also observed. As a result of the study, it was explained that most of the injuries seen in the taekwondo competitions did not require the medical intervention and the lower extremities were mostly injured in these competitions. In the light of these findings, it could be said that these parts be protected during the competitions and the defense techniques be different.
\end{abstract}

Key words: İnjuries, Taekwondo, University championchips,

\section{INTRODUCTION}

The art of fighting has been around for thousand of years. There are even references to martial arts in ancient Greece and Egypt. There are many styles of martial arts some commonalities may be found in techniques and training methods (15). In general styles may be broken down in to several categories:striking-based system, grappling or throwing systems, weapons bases-system, and health-based systems (15). Korean taekwondo is an asiatic fighting sport practised all over the world. Originally taekwondo was a discipline in the Korean army and originated about thirteen hundreds years ago (14). Taekwondo is a Korean martial art practiced in over 184 countries. The sport gained full medal status at the 2000 Olympics in Sydney, Australia, 1 and draws participants of all ages due to its perceived fitness benefits and popularity (3). Zemper and Pieter (17) found injury rates for
American elite male Taekwondo athletes to be 127.4/ 1,000 athlete-exposures and for females, 90.1/1,000 athlete- exposures. One athlete-exposure (A-E) refers to one athlete being exposed to the possibility of being injured. Since there are always two athletes competing during any one bout, there are two athlete-exposures per bout $(4,5)$. In a later study, Pieter et al. (11) reported injury rates of 139.5/1,000 A-E and 96.5/1,000 A-E for European men and women, respectively (11). However, at a recreational tournament in the United Kingdom, the men (51.3/1,000 A-E) sustained statistically significantly more injuries than the women $(47.6 / 1,000 \mathrm{~A}-\mathrm{E})(12)$. In this study it was aimed to determine the type of sports injuries occurring in Interuniversity Taekwondo Championship made in Marmaris, Muğla and to discuss sports injuries occurring in martial arts in the light of the literature. 


\section{MATERIAL \& METHOD}

287 elitist sportsmen (178 males and 109 females) attending to Interuniversity Taekwondo Championship made in Ordu in April of 2011 were taken into this study. Injuries were grouped as injuries necessitating and not necessitating medical treatment. Injuries were recorded by two national team coaches and two national sportsmen and championship doctors. In addition, every sportsman was said to inform observers when any injury occurred. The data were recorded in the way the shape of injury, the belt grade of injured player, professional sportsmanship time, violence and mechanism of injury and if it necessitates any medical treatment. Physical examinations of sportsmen were not made before the contest. Injuries were recorded by determining with verbal statements of those treated by championship doctors and of injured sportsmen. Injuries were separated into sub-classes as those being and not being in the level to necessitate medical treatment and those being in the level to necessitate stopping the match, and were proportioned to the total injuries number. Injuries being in the level necessitating medical treatment were separated into two sub-groups as brain traumas and traumas except this. The number of injuries was recorded in two ways as total injuries number per match and in sportsman total injuries number per the match he held. Brain traumas were classified according to Colorado concussion classification (According to this, first grade injury confusion; no memory loss or blackout of consciousness; second grade injury confusion but there is memory loss and there is blackout of consciousness in the third grade).

The statistic program "SPSS" was used to analyse the data gathered. Descriptive statistics summarised body injuries factors such as sample size, number of males and females, age range, and mean age per competition period for all competitions. Means and proportions described the outcome measures (number of reported injuries, injury rates, and body part injured).

\section{RESULTS}

The total 46 universities participated in championship and the contest continued for 3 days. Mean age of all sportsmen was $21,65 \pm 0,88$, that of female sportswomen was $21,9 \pm 0,71$, that of male sportsmen was $20,46 \pm 0,94$. All athletes of the year were over three years the average of professionalism.
All sportsmen had black belt. In the championship of 3 days, the total 271 matches were made. In the fist day in males matches of $58 \mathrm{~kg}, 78$ and $84 \mathrm{~kg}$, in females matches of 42 and $59 \mathrm{~kg}$; in the second day in males matches of 54,62 and $72 \mathrm{~kg}$; in the third day in males matches of 67 and $84+\mathrm{kg}$, in females matches of 55, 67 and 72+ were performed. The total injuries number was found out 539.123 of these injuries were in the upper extremity, 1 of these was in the face region (nose break), and the remaining 415 were in the lower extremity.39 matchs had to be stoped because of the injuries. 16 of these injuries have caused sportsmen not to continue the match and 2 of these 16 injuries have become in the level necessitating medical treatment. In Table 1 and 2, injury frequencies and regions were given. The most common injury region was in the lower extremity (\%77). In the lower extremity, the mostly injured parts were foot, ankle and tibia front part. The most common injury type was hematoma occurring in the foot dorsum and sprain in the foot metatarsal bones. There were 148 edemas (27\%), 84 hematomas on dorsum of feet, 37 hematomas on hip (25 strikes, 12 ones after falling down), 9 sprains in ankle, 7 hematomas on toe, 20 hematoma on thigh, 6 edemas on knee-joint after striking down. In upper extremity, there were 90 hematomas, 6 contusions in forearm, 1 fracture in radius, 8 hematomas on metacarpus, 3 hematomas on wrist, 14 edemas on finger. Injury frequency was in heavier and treatment requiring level in males and especially in high weights. Total 38 injuries required the medical intervention. Of these injuries, 3 fractures (nose, metacarpus and radius), 6 finger sprain, 7 sprains in 20 hematomas of the thigh, 6 sprains in ankle, 9 sprains developing after hematomas on the front part of 104 tibias, 7 sprains developing after strike in forearm were analysed. Except for three medical situations developing after fractures, all other injuries were treated with bandaging, ice application and resting. It was determined that 1 of injuries necessitating advanced treatment was the nose break, 1 of those was the break in the hand metacarpal bone, two of them were the break in the radius. The technique causing the most widespread injury was the one made with the kick. The most often injury type had developed due to blocks made with the upper extremity $118(\% 21)$ or lower extremity against the kick technique 84 (\%15). The nose break happened due to the kick hit on the face. The body injuries never occurred because the body part was being protected 
with a special protective during the fighting. All of injuries being in the level necessitating treatment occurred due to the kick and all of injuries preventing the match from being continued occurred due to the foot or knee collisions. The great majority of the foot injuries occurred due to the collision of the foot with the rival's wrist $97(\% 18)$, hand $26(\% 4)$, knee $(\% 1)$, the front outer part of the

Table 1. Upper Extremty İjuries

\begin{tabular}{lcccccccc}
\hline & Shoulder & Arm & Forearm & Wrist & Hand & Hand Finger & Neck & Nose \\
\hline Sprain & 0 & 0 & 0 & 0 & 0 & 14 & 0 & 0 \\
Hematom & 0 & 0 & 90 & 3 & 8 & 0 & 0 & 0 \\
Broken & 0 & 0 & 1 & 0 & 1 & 0 & 0 & 1 \\
Scratch & 0 & 0 & 6 & 0 & 0 & 0 & 0 & 0 \\
Epistaxis & & & & & & & & 1 \\
\hline
\end{tabular}

\begin{tabular}{|c|c|c|c|c|c|c|c|}
\hline & Hip & Thigh & Knee & Tibia & Ankle & Foot Dorsi & Foot Fingers \\
\hline Sprain & 0 & 0 & 6 & 0 & 9 & 0 & 0 \\
\hline Hematom & 37 & 20 & 0 & 104 & 84 & 148 & 7 \\
\hline Broken & 0 & 0 & 0 & 0 & 0 & 0 & 0 \\
\hline Scratch & 0 & 0 & 0 & 0 & 0 & 0 & 0 \\
\hline
\end{tabular}

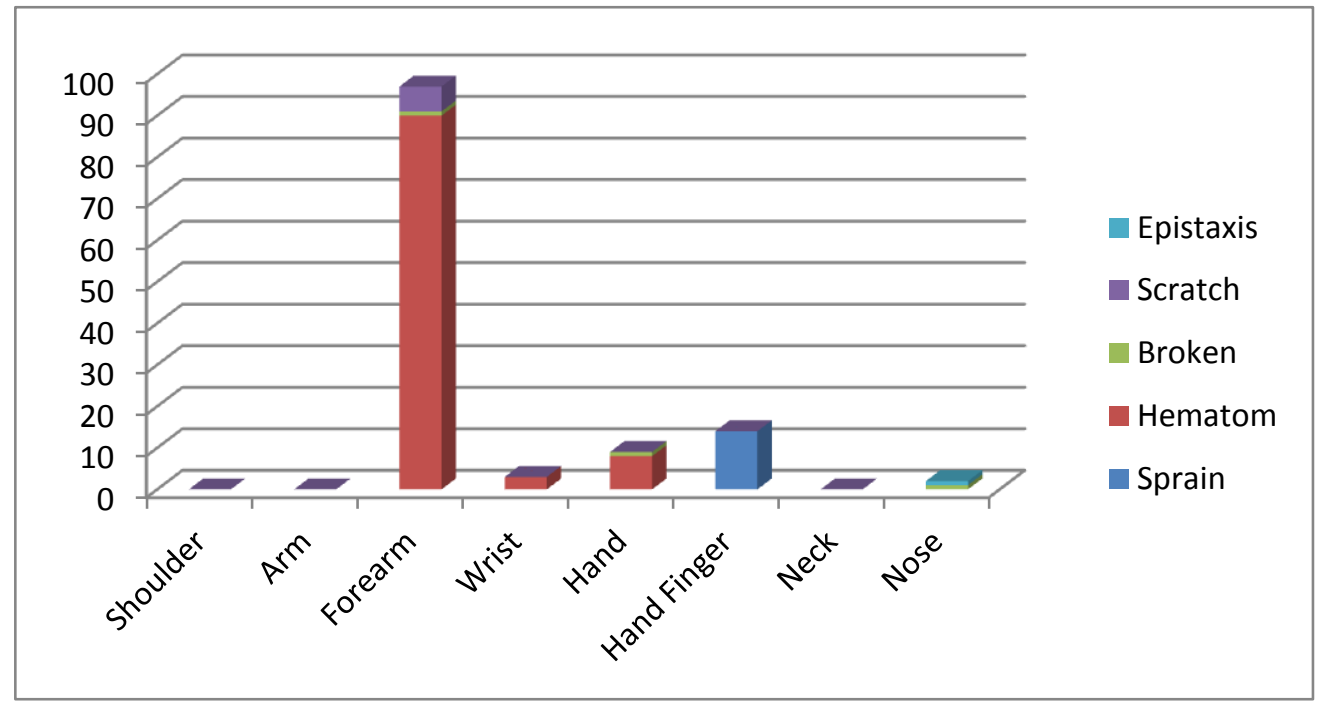

Figure 1. Upper Extremty İnjuries

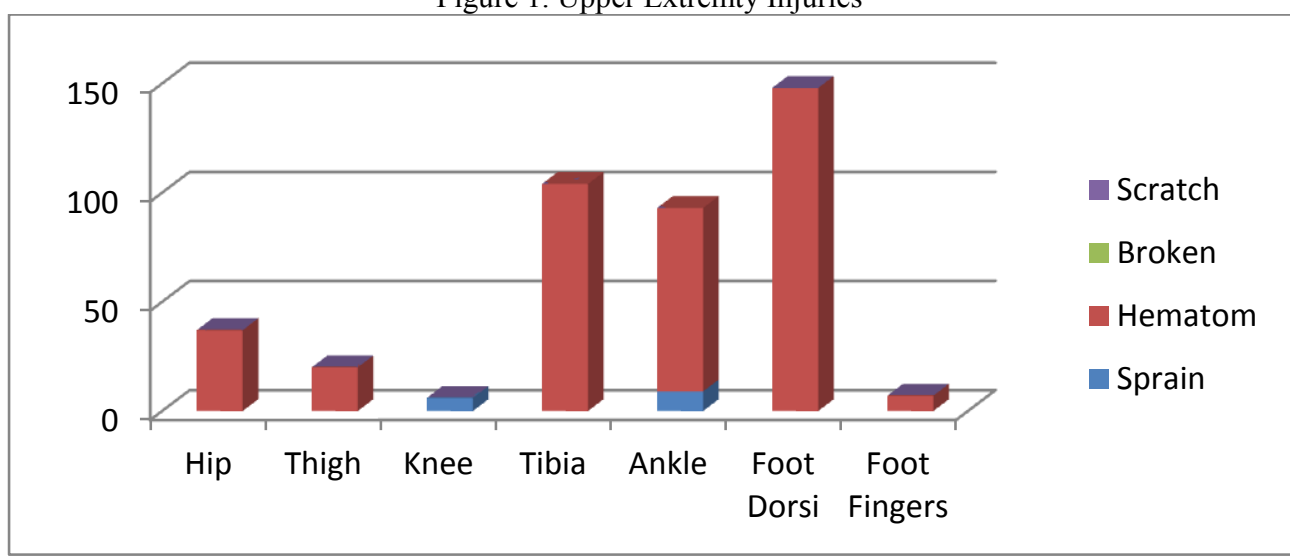

Figure 2. Lower Extremty İnjuries 


\section{DISCUSSION}

The Korean martial sport of full-contact taekwondo has become increasingly popular among adults and children alike (13). Martial Arts is a general term that describes the art of combat and self-defense. These arts involve the use of different body parts and various weapons. A large variety of martial arts exist, each with a distinct history, philosophy and set of techniques (6). Korean taekwondo is an Asiatic fighting sport practised all over the world. Originally taekwondo was a discipline in the Korean army and originated about thirteen hundred years ago. The word taekwondo can be translated as 'the art of foot and hand'. Tae means a kick or push with the foot, Kwon means clenched fist or the blow that crushes; Do means the spirit, way or method (14). Taekwondo, which originated in Korea more than 1000 years ago, is more sport than self defense oriented. In 2000, Taekwondo became recognized as an official sport at the Sydney Olympics. Taekwondo is a full contact free-sparring sport which awards points for head contact. As such, there has been increased interest in injury rates in the sport, especially relating to head injuries (4). A beginner starts at a rank of 'white belt' and when he or she has achieved sufficient proficiency of Taekwondo skills, they move through several higher ranks, respectively the colored belts (In increasing rank: Yellow, Orange, Green, Purple, Blue, Brown, Red), and black belts (with increasing rank based on Dan level, from 1st to 9th) (3). As expected in a collision sport, the contusion was the most frequently occurring injury type in both male and female Taekwondo athletes (5). At the elite level, more serious injuries such as fractures and cerebral concussions also occur (5). The incidence rate of injury for men attending in different taekwondo competitions was reported in a range of 20.5 to 168.4 injuries for each 1000 men (16). According to the existed evidence, the lower limbs is the most prevalent place of injury followed by the head, neck and vertebral column (16). Contusion and sprain were also have been found as the most prevalent types of injuries sustained (16). American elite athletes recorded injury rates of 127.4/1,000 A-E (men) and 90.1/1,000 A-E women) (5), while European colleagues had rates of 139.5/1,000 A-E (men) and 96.5/1,000 A-E (women) (5). Oler et al. reported that the combined injury ratios were $3.4 \%$ when 300 young male and female taekwondo sportsmen were taken as basis (7). In our study, 539 injuries were observed in 271 competitions in total.
The rate of injury per the competition was 1,98 . The rate per the sportsman after injury was 1,87 . However injury ratios occurring in the championship and injury ratios occurring in the matches necessarily will be different. So to present injuries occurring during the championship as injury frequency occurring in general martial arts will be hardly true. The great majority of injuries occurring is acute and starts suddenly. Only in two studies it was reported that they started late. Injuries in our study had sudden and acute starting. It was reported that in Pieter taekwondo all slow starting injuries were 14 in males and 35 in females. However any information concerning frequency, density and time of factors causing this was not given (8). The rate of injuries (69.5 per $1000 \mathrm{~A}$-Es) in Iranian athletes is lower than the rates reported from most of European and American countries (16). Although Beis et al. found 20.5 injuries per 1000 AEs (lowest reported rate of injury in the literature) and also Pieter et al. reported 51.3 injuries per 1000 A-Es for taekwondo athletes, it seems the rate was found in Iran could be considered lower than the mean of injury rates reported previously (16). The incidence rate of injury for men attending in different taekwondo competitions was reported in a range of 20.5 to 168.4 injuries for each 1000 men (16). According to the existed evidence, the lower limbs is the most prevalent place of injury followed by the head, neck and vertebral column (16). Contusion and sprain were also have been found as the most prevalent types of injuries sustained (16). The study was a summation of 9 years of data of competition injury reports, which included 904 injury reports spanning 58 individual competitions (3). The three most common locations of presenting injury were the head (19\%), foot (16\%), and thigh (9\%). The most common mechanism of presenting injury was found to be a defensive kick (44\%), followed by an offensive kick (35\%). The most commonly diagnosed injuries were contusions (36\%), sprains (19\%), and strains $(15 \%)$. Coloured belts had a higher incidence of contusions, while black belts sustained more joint irritation injuries. Black belts were more likely to suffer multiple injuries (3). In taekwondo, the lower extremities sustain most of the injuries (36.7-65.0\%) (9).The great majority of the foot injuries occurred due to the collision of the foot with the rival's wirst 97( \%18), hand 26(\%4), knee (\%1), the front outer part of the thigh and tibia while kicking 104(\%19), foot and ankle was 248 (\%46). On the other hand, the spine/trunk was found to be injured most often in 
one judo study and not at all in karate and taekwondo (9). The spine injuries didn't dedecte in our sudy.The foot is the most often injured lower extremity (\%46) part in taekwondo compared to judo and karate. In a study it was determined that the head and neck injuries were the most often injured region in taekwondo tournament (7). The head and neck injuries wasn't dedected in our study. Kazemi et al. made, 2\% abrasion, $7 \%$ concussion, $12 \%$ contusion, $2 \%$ epistaxis, $11 \%$ laceration and $23 \%$ sprain were determined. In canadian national taekwondo championships (5). In our study these ratios $\% 1$ abrasion, $\% 5$ sprain $\% 1$ epistaksis, \%94 hematomas were also determined. Epistaxis was reported in taekwondo as well as in other martial arts (9). In our study epistaxis was determined in 1 case, depending on the nose break. In our study, during blocks made against the kick, 1 radius break, 6 abrasion in the fore arm and 101 hematomas (\%18) occurred. Breakfalls are common to the martial arts. The goal of practicing falls, or breakfalls, is to reduce the chance of injury in the event of a fall during training or when in a fight. Although each style may teach a different method of falling, the principles are quite similar (15). In our study any injury based on falls was not determined because in taekwondo the techniques towards beating down were not being permitted in the matches. Contusions and hematomas are so common in the martial arts that they are frequently unreported (2). The most widespread type of injury in our study was determined as contusions and hematomas as well (\%94). As expected, the contusion was found to be the most frequently occurring injury type in other studies on Taekwondo

\section{REFERENCES}

1- Beis K, Tsaklis P, Pieter W, Abatzides G. Taekwondo competition injuries in Greek young and adult athletes. Eur J Sports Traumol rel res 2001, 23(3):130-136

2- Birrer RB, Birrer CD. Unreported injuries in the MA. Br J Sports Med 1983;17(2):131-4

3- Kazemi M, Chudolinski A, Turgeon M, Simon A, Ho E, Coombe L. Nine year longitudinal retrospective study of Taekwondo injuries. J Can Chiropr Assoc. 2009 Dec;53(4):27281.

4- Kazemi M, Shearer H, Choung YS. Pre-competition habits and injuries in Taekwondo athletes. BMC Musculoskelet Disord. 2005 May 27;6:26. injuries $(11,17,1)$. The sprain ranked in the top three of most frequently occurring injuries across several tournaments (5). The contusion was also the most oftenoccurring injury in karate, while the epistaxis ranked second in Dutch men and women (5). Although protective equipment is now being used as suggested by Siana et al., it also should be noted that after repeated impact the padding may no longer be adequate (14). In injuries occurring in the head and neck region, the most widespread type of injury is contusions and lacerations (10). Many contusions can be minimized by the use of appropriate headgear during sparring. Contusions, sprains, and strains are the most common neck injuries (15). In our study any injury due to hits on the neck was not determined. In our study any injury concerning the shoulder was not determined. As a result, the high velocities and momentum levels generated during taekwondo kicking in combination with a lack of proper blocking as found in this study should give rise to serious concern about the medical implications of full contact taekwondo (17).

As a result of the study, it was explained that most of the injuries such as hematoma, edema, contusion seen in the taekwondo competitions were not at the level of requiring intensive medical intervention and the lower extremities were mostly injured in these competitions. In the light of these findings, it could be said that these parts be protected during the competitions, the defense techniques be in different ways and the relevant practices be given importance.

5- Kazemi M, Pieter W. Injuries at the Canadian National Tae Kwon Do Championships: a prospective study. BMC Musculoskelet Disord. 2004 Jul 27;5:22.

6- McPherson M, Pickett W. Characteristics of martial art injuries in a defined Canadian population: a descriptive epidemiological study. BMC Public Health. 2010 Dec 30;10:795.

7- Oler M, Tomson W, Pepe H, Yoon D, Branoff R, Branch J. Morbidity and mortality in the martial arts: a warning. $J$ Trauma. 1991 Feb;31(2):251-3.

8- Pieter W, Fife GP, O'Sullivan DM. Competition injuries in taekwondo: a literature review and suggestions for prevention and surveillance $\mathrm{Br}$ J Sports Med. 2012 Jun;46(7):485-91.

9- Pieter W. Martial arts injuries. Med Sport Sci. 2005;48:59-73.

10- Pieter W, Zemper ED. Head and neck injuries in young taekwondo athletes. J Sports

Med Phys Fitness. 1999 Jun;39(2):147-53. 
11- Pieter W, Van Ryssegem G, Lufting R, Heijmans J. Injury situation and injury mechanism at the 1993 European Taekwondo Cup. J Hum Mov Stud 1995, 28(1):1-24.

12- Pieter W, Bercades LT, Heijmans J. Injuries in young and adult Taekwondo athletes. Kines 1998, 30(1):22-30.

13- Pieter W, Zemper ED. Injury rates in children participating in taekwondo competition. J Trauma. 1997 Jul;43(1):89-95.

14- Siana JE, Borum $\mathrm{P}$, Kryger $\mathrm{H}$ : Injuries in taekwondo. $\mathrm{Br} \mathrm{J}$ Sports Med. 1986 Dec; 20(4): 165-6.
15- Terry CM. The marital arts. Phys Med. Rehabil Clin N Am. 2006. Aug; 17(3): 645-76

16- Ziaee V, Rahmani SH, Rostami M. Injury rates in Iranian taekwondo athletes; a Med. 2010 Mar;1(1):23-8.

17- Zemper ED, Pieter W. Injury rates during the 1988 US Olympic Team Trials for taekwondo. Br J Sports Med 1989,23(3):161 